\title{
Information and decision-making needs of psychiatric patients: the perspective of relatives
}

\author{
Sarah Liebherz ${ }^{\text {Corresp., }}{ }^{1}$, Lisa Tlach ${ }^{1}$, Martin Härter ${ }^{1}$, Jörg Dirmaier ${ }^{1}$ \\ ${ }^{1}$ Department of Medical Psychology, University Medical Center Hamburg-Eppendorf, Hamburg, Germany \\ Corresponding Author: Sarah Liebherz \\ Email address: s.liebherz@uke.de
}

Background. Mental illness may strongly affect relatives' lives. Therefore, it is important to empower relatives by providing health information according to their preferences.

Methods. An online cross-sectional survey was conducted using a purpose-designed questionnaire on online health information and decision-support needs.

Results. Prevalent reasons for online health information search of the 185 participating relatives were the need for general information and the insufficiency of the information given by the health care provider. The most difficult treatment decisions concerned the treatment setting (inpatient or outpatient) as well as the psychopharmacological treatment.

Discussion. Since psychiatric patients' relatives report extensive information and decision-support needs, it is essential to address their needs in health information material. Assessment of relatives' needs when developing health information materials is recommended. 


\section{Information and decision-making needs of psychiatric patients: the 2 perspective of relatives}

3

4 Sarah Liebherz, Lisa Tlach, Martin Härter, Jörg Dirmaier

6 Department of Medical Psychology, University Medical Center Hamburg-Eppendorf,

7 Martinistraße 52, W 26, Hamburg, Germany

8

9 s.liebherz@uke.de

10 1.tlach@uke.de

11 m.haerter@uke.de

12 dirmaier@uke.de

13

14 Corresponding author:

15 Sarah Liebherz, $\mathrm{PhD}$

16 Department of Medical Psychology

17 University Medical Center Hamburg-Eppendorf

18 Martinistraße 52, W26

19 D-20246 Hamburg

20 Germany

21 Tel: +49(0)40 741057969

22 Fax: $+49(0) 40741054940$

23 s.liebherz@uke.de 


\section{Abstract}

25 Background. Mental illness may strongly affect relatives' lives. Therefore, it is important to 26 empower relatives by providing health information according to their preferences.

27 Methods. An online cross-sectional survey was conducted using a purpose-designed questionnaire 28 on online health information and decision-support needs.

29 Results. Prevalent reasons for online health information search of the 185 participating relatives 30 were the need for general information and the insufficiency of the information given by the health 31 care provider. The most difficult treatment decisions concerned the treatment setting (inpatient or 32 outpatient) as well as the psychopharmacological treatment.

33 Discussion. Since psychiatric patients' relatives report extensive information and decision-support 34 needs, it is essential to address their needs in health information material. Assessment of relatives' 35 needs when developing health information materials is recommended. 


\section{Introduction}

37 Mental illness - especially in severe cases - may significantly influence the lives of people in the 38 affected persons' immediate surroundings (e.g. relatives, carers and friends). ${ }^{1}$ Living with or caring for a person with a mental illness may increase the relatives' stress level and may cause health problems and a reduced quality of life (Ali et al. 2014; Skundberg-Kletthagen et al. 2014; Weimand et al. 2010). As caring for a mentally ill person may be emotionally challenging and lead to grief, fear and isolation, carers themselves need support (NICE 2014).

To deal with these various challenges, empowerment for relatives through comprehensive information about the affected persons' illness is useful (Friedrich et al. 2012). Previous studies on relatives' information needs (mostly focusing on schizophrenia or affective disorders) have confirmed relatives' interest in (written) information about the illness and emphasize the need for psychoeducation. However, the demand for information often remains unmet (Angermeyer et al. 2000; Gantt et al. 1989; Gümüș 2008; Mueser et al. 1992; Wancata et al. 2006; Wei et al. 2010). Frequently, relatives do not know the correct diagnosis, do not get adequate information on the current medication or are not able to recognize the symptoms (Gantt et al. 1989; Gaskill \& Cooney 1991; Wittmund et al. 2001). They report a lack of involvement in the treatment process and often feel alone as they do not know other people being in the same situation (Gaskill \& Cooney 1991). Various studies show that unmet information needs of relatives concern medical and psychiatric treatment, medication and side effects, early warning symptoms, sleeping problems, communication with relatives, denial and noncompliance, dealing with common problems, burnout and stress, the health care system, social relationships, coping with bizarre and assaulting behavior, as well as patient rights (Chien et al. 2003; Gümüş 2008; Mueser et al. 1992; Pollio et al. 1998; Sung et al. 2004; Wancata et al. 2006; Wei et al. 2010). Therefore it seems necessary to inform relatives on these issues. Besides information leaflets, one way to enable and encourage patients and their families and friends to participate in medical decisions is to provide high quality and feasible (web-based) patient decision aids. Patient decision aids are evidence-based tools that support people to deliberate, independently or in collaboration with others, about choices they face by considering relevant attributes of the options (Elwyn et al. 2009). In addition to unmet

\footnotetext{
${ }^{1}$ As the majority of the participants of our survey are family members of the affected persons and the cited literature refers mostly to family members, we use the term "relative" here, even if other people from the affected persons" immediate surroundings are also included.
} 
64 information needs (especially concerning treatment options), patient decision aids may also 65 address unmet decision-support needs.

66 As a low-threshold opportunity, the Internet bears the potential to deliver interactive, personalized, 67 and individualized content at comparatively low costs to a large number of users at the time, place 68 and learning speed the individual user prefers (Weymann et al. 2013). Internet interventions can 69 help to inform about mental disorders, to find local treatment services and to prepare for doctor 70 contacts.

72 Patient education and patient involvement are relevant components of shared decision-making 73 (SDM). SDM is defined as an interactional process in which the patient and the physician (or 74 another health care provider) aim to reach a decision together that is based on shared information and the best available evidence (Härter 2004). The definition of SDM focuses on the involvement

76

77 78 79 80 of patient and health care provider. However, relatives are often involved in treatment decisions also - for example to support the patient, both during the medical encounter to provide emotional, informational, or practical support (Wolff \& Roter 2008) or when discussing the issue without the health professional. Support of relatives during medical encounters can change the situation, e.g. in influencing the patient's relationship with the physician and in increasing the complexity of the encounter (Beisecker \& Moore 1994). A recent review of triadic medical encounters (LaidsaarPowell et al. 2013) found that some companion behavior were helpful (e.g. informational support) while other were less helpful (e.g. dominating or demanding behaviours). Preferences for involvement of others varied widely. The authors give recommendations for health professionals including encouragement/involvement of accompanying persons, emphasis of helpful companion behaviours as well as clarification of the role preferences of the patient and the accompanying person.

Assessment of service users' and experts' views on the information and decision-support needs of patients with mental disorders is suggested as being one key element in the systematic development of high quality decision aids (Elwyn et al. 2006). A recent systematic review shows that research on information and decision-making needs is largely restricted to schizophrenia and depressive disorders (Tlach et al. 2015). Moreover, evidence on decision-support needs from the perspective of patients' families and friends is lacking. It can be assumed that relatives can have 
95 different roles in the decision-making process, e.g. 1) If the affected person is incapable to make 96 the decision alone (e.g. during a psychotic episode), the relative can make the decision - e.g. as a 97 legal representative. 2) The relative can be an important advisor and can support the affected 98 person to make the decision. 3) The relative can be affected by the decision made by the affected 99 person (e.g. if the affected person takes psychotropic drugs or not). 4) The relative can be faced 100 with decisions concerning their own lives (e.g. getting professional support themselves, keeping 101 in touch with the affected relative during acute illness episodes or not).

102

103 Against this background, this paper aims to investigate (online) information needs of psychiatric 104 patients' relatives. Moreover, this paper has a focus on treatment decisions in the treatment course 105 of the affected person and concentrates on the following questions:

1061 . Which kind of treatment decisions do the relatives remember?

1072 . Which kind of decisions do they remember as difficult?

108 All relevant treatment decisions remembered by the relatives are explored - regardless of their 109 own role in the decision-making process. 
110 Materials and Methods

111 An online cross-sectional study using a purposed-designed survey (self-rating) addressing people

112 reporting experience with mental disorders as a relative, friend or acquaintance was employed.

113 The questionnaire was purpose-designed, as there was no questionnaire on mentally ill peoples'

114 relatives' decision-support-needs.

115

116 Survey development

117 The choice of the topics focused in the survey was based on a systematic review concerning 118 information and decision-making needs (Tlach et al. 2015) as well as contact with experts in the 119 field.

120 The survey was pilot-tested for clarity, ease of use and smooth functioning with 27 participants 121 (research assistants and student assistants). It was also adjusted with different experts in the field 122 of (e-)mental health and SDM research. The items on treatment decisions derived from evidence123 based treatment option named in the current treatment guidelines. Since these options differ 124 between different mental health conditions, the questions were tailored depending on the affected 125 persons' mental illness stated. Since the survey was developed as a pre-requisite for the 126 development of web-based patient decision aids, an online sample was examined.

127 The questionnaire involved five items on sociodemographic characteristics of the participants (age, 128 sex, level of education, partnership status, country of birth), one item concerning the clinical 129 characteristics of the affected person (self-report primary diagnosis) and one item on the relation 130 to the affected person (partner, parent, child, other relative, friend or acquaintance). The main part 131 focused four sections:

132 1. Internet use: three items addressed the frequency of general Internet use, Internet use on 133 general health topics and Internet use on the affected persons' mental disorder on a five134 tier scale: (almost) daily, at least once a week, at least once a month, less than once a month, 135 never

2. Online health information needs: two items addressed the reason for information search (six pre-specified answer options) as well as the sort of required information (seven prespecified answer options). One additional option "other" in both items with a free-text answer option was applied. Multiple answers were allowed. The pre-specified answer 
140

141

142

143

144

145

146

147

148

149

150

151

152

153

154

155

156

157

158

159

160

161

162

163

164

165

166

167

168

options were based on relevant information needs derived from literature search (Tlach et al. 2015) as well as contact with experts in the field.

3. Role in decision-making: preferred as well as actual role in decision-making with two items adapted from the Control Preference Scale (Degner et al. 1997). They participants had to state (from their point of view) if the affected person or the physician should make/has made the decision alone or together - in accordance with the concept of shared decision-making.

4. Treatment decisions: sixteen items concerning evidence-based treatment options for the respective illness - identified through systematic literature (Tlach et al. 2015) and guideline search (DGPPN et al. 2015; NICE 2014). The items included the following topics: treatment setting, start of treatment, psychopharmacological treatment, psychotherapeutic treatment, combined treatment, alternative treatment. Participants stated if their affected relative ever had made these decisions and (if yes) assessed the difficulty of these decisions (very difficult, rather difficult, rather simple, and very simple). Participants had the possibility to specify other relevant decisions in a free text field introduced by the question: From your point of view, are there other relevant decisions during the course of your relative's illness?

\section{Data collection}

This survey was performed with EFS survey (QuestBack 2012). Participants were recruited online on the e-mental health portal www.psychenet.de. The portal provides information leaflets, patient decision aids and information on the health care system as a key part. The target group of the portal comprises people affected by mental disorders, their relatives, health care providers as well as other interested people (Dirmaier et al. 2016). During the investigation period from January to April 2013, 15.000 visitors per month were registered through web analysis software on the emental health portal. The survey was announced at all sub-areas of the portal, introduced by the question: "What kinds of decisions are relevant during the course of a mental disorder?"

Additionally, 48 cooperating self-help groups as well as 10 cooperating hospitals in the area of Hamburg were contacted via e-mail to announce the survey. 
169 Approval for the study was obtained from the ethics committee of the Hamburg Medical 170 Association (Process number: PV4157). All participants were asked for written informed consent. 171 Only participants who gave written informed consent to participate (asked at the beginning of the 172 questionnaire) as well as consent to data use (asked when participants had finished the 173 questionnaire) were included in the analyses.

174 Participants reporting experience with a relative, friend or acquaintance with a mental illness and 175 being at least 18 years old were included. All data were self-reported.

176

\section{Data analysis}

178 Statistical analyses were performed applying the statistical software package PASW Statistics 18 179 (SPSS 2009). As this research project was explorative, data were primarily evaluated by 180 quantitative descriptive data analysis (absolute and relative frequencies, means and standard 181 deviations). $\mathrm{Chi}^{2}$-tests (exact significance, two-tailed) were applied to test if the preferred role in 182 decision-making (active, shared or passive) or the accordance between the preferred and the actual 183 role, had an influence on the decisional conflict. Answers concerning the items on treatment 184 decisions were dichotomized for this analysis (difficult versus simple decisions). Qualitative data 185 analysis techniques (conventional content analyses) were used to analyze the free text answers 186 concerning information needs and relevant decisions, applying an inductive approach (Hsieh \& 187 Shannon 2005; Mayring 2000). This method is considered appropriate when existing theory or 188 research literature on a phenomenon is limited or unclear (Hsieh \& Shannon 2005). Responses 189 were categorized into superordinate domains. Responses that included a number of themes were 190 subdivided into various units and separately categorized. The coding was carried out by one 191 student assistant and validated by two members of the research team (SL, LT). 
192 Results

193 Patient flow

194 During the investigation period from January to April 2013, $n=437$ relatives, friends or 195 acquaintances of persons with a mental illness started the online-survey. A total of $\mathrm{n}=372(85 \%)$ 196 gave consent to participate, $\mathrm{n}=200$ (46\%) finished the questionnaire and $\mathrm{n}=188(43 \%)$ 197 participants gave informed consent to data use. Three participants had to be excluded due to 198 implausible data, so the final sample consisted of $n=185$ participants $(42 \%)$.

199

200 Sample description

201 Three quarters of the surveyed (77\%) were female. Age ranged from 19 to 82 years (see Table 1). 202 In most cases, participants were parents (35\%) or partners (34\%) of a person with mental illness. 203 The diagnosis most frequently mentioned was bipolar disorder/mania (45\%).

204

- Please insert Table 1 here -

205 Internet use

206 While almost all participants (99\%) reported daily or at least weekly Internet use, 46\% reported at 207 least weekly internet use for general health information search and $28 \%$ reported at least weekly 208 Internet use for information search specifically on their relatives' mental illness (see Fig. 1).

209 - Please insert Figure 1 here -

210 Reasons for online health information search

211 The most prevalent reasons for online health information search were the need for general 212 information on the relatives' mental disorder (67\%) and the insufficiency of the health care 213 provider's information (43\%; see Fig. 2).

214

- Please insert Figure 2 here -

215 Other reasons for online health information search (free-text answers)

216 Other reasons were the search for support for relatives (for example self-help groups), the search

217 for treatment possibilities - other than medication -, the feeling of being unable to cope, the wish 
218 to feel sympathetic to the relative and the search for proves that the diagnoses exists - because 219 other family members refused to recognize this.

\section{Online health information needs}

221 More than a half of all participants mentioned the need for information tailored to relatives $(70 \%)$, 222 general information on the affected relative's disease $(68 \%)$, tips on dealing with the disease $223(62 \%)$, information about treatment options (60\%) as well as information about chances, risks and 224 side effects of the treatment options (54\%; see Table 2).

Other online health information needs (free-text answers)

227 In the free-text fields, the participants also stated the need for information on protection of the 228 affected person's children, books or films, the current state of research, heredity as well as civil 229 rights.

\section{Role in decision-making}

231 Two thirds $(65 \%)$ of the participants would prefer a shared decision of the affected person and 232 his/her health care provider, while only about one third (38\%) remembered the last decisions as 233 shared ones. In total, $48 \%$ of the participants experienced a role according to their preferences, 234 while $52 \%$ did not. There were more decisions made by the affected person or the physician / 235 psychotherapist alone than preferred (see Fig. 3).

\section{Treatment decisions and decisional conflicts}

238 Relatives had to state for each treatment decision, if the affected person ever made this decision 239 and if they remembered the decision as difficult or not. The most difficult treatment decisions 240 (remembered as 'rather difficult' or 'very difficult' by more than half of the participants) concerned 241 the treatment setting (inpatient or outpatient) as well as the psychopharmacological treatment. 242 Decisions on taking psychotropic drugs, getting outpatient or inpatient treatment and starting 243 psychotherapy were remembered as 'already made' by at least 80 per cent of all participants. The 244 least common decisions (50\% or more did not meet this decision yet) are: psychotherapy OR 245 psychotropic drugs, the application of alternative treatments, the decision to work through a self- 
246 help book or not and the decision if the affected relative should quit the current psychotherapy (see 247 Table 3).

249 The difficulty of making a decision as a percentage of those who had actually made the decision 250 is described in the supplemental material (Supplemental Figure 1). However, the decisions 251 remembered as most difficult, remain almost the same.

252 Role in decision-making and decisional conflicts

253 There were no significant differences in the perceived difficulty of any treatment decision 254 depending on the preferred decision-making role (active, shared or passive) or the accordance 255 between the preferred and the actual role, except concerning one item: More participants reporting 256 an accordance between the preferred and actual role, remembered the decision 'starting a 257 psychotherapy in addition to psychopharmacological treatment or not' as difficult (see 258 Supplemental Tables 1\&2).

259 Other relevant decisions (free-text answers)

260 Other decisions relevant for relatives during the course of disease of the affected person focused 261 on dealing with the disease (e.g. informing other relatives or the employer about the mental illness, 262 noticing that the illness restarts, dealing with a lack of illness insight), treatment (e.g. finding the 263 best hospital, physician or psychotherapist, relying on the health care system, aftercare, 264 compulsory hospitalization), being included in the affected persons' life and self-care (e.g. being 265 involved in the relative's life, protecting themselves and other relatives, getting support and being 266 able to stand the strain, keeping in touch with the affected relative during acute illness episodes), 267 lifestyle changes, and life planning (e.g. need for a legal supervision, housing situation, separation 268 from the affected partner, kind and extent of occupational activity, applying for a disabled person's 269 pass, giving up one's own job). 


\section{Discussion}

271 The information and decision-support needs of psychiatric patients' relatives were studied by 272 including 185 participants in an online cross-sectional survey. To our knowledge, this is the first 273 survey on online health information and decision-support needs of psychiatric patients' relatives. 274 Most participants were close relatives of an affected person (partner, parent or child). Concordant 275 with previous studies (Angermeyer et al. 2000; Chien et al. 2003; Gaskill \& Cooney 1991; Gümüş 276 2008; Mueser et al. 1992; Sung et al. 2004; Wancata et al. 2006), the participants reported a strong 277 need for general information on the affected person's mental disorder (e.g. symptoms and 278 treatment options), for tips on dealing with the disease and for information tailored specifically to 279 relatives. They also mention the insufficiency of the health care provider's information as main 280 reason for online health information search.

281 In comparison, samples with participants affected from bipolar disorder/mania, unipolar 282 depression or anxiety disorders (Liebherz et al. 2015a; Liebherz et al. 2015b) mentioned general 283 information on the disease, information about treatment options as well as tips on dealing with the 284 disease as main interest.

285 Concerning treatment decisions, decisions on the treatment setting (inpatient or outpatient) and on 286 pharmacological treatment were remembered as most difficult. These decision-making topics are

287 288 289

290

291

292

293

294

295

296

297 298

299 300 consistent with those mentioned by a sample of patients with affective disorders (Liebherz et al. 2015b): The three most difficult decisions overlapped in these two samples. However, the percentage of people remembering these decisions as "difficult" was lower in the patient sample than in the relatives sample, especially concerning the decision on inpatient versus outpatient treatment (53 versus 70\%). A sample of patients with anxiety disorders (Liebherz et al. 2015a) reported an overall lower percentage of decisions remembered as "rather or very difficult", the three most difficult decisions were "starting a psychotherapy or not" (33\%), "inpatient or outpatient treatment" (32\%) and "taking psychotropic drugs or not" $(30 \%)$.

The decision between inpatient and outpatient treatment may be particularly relevant in Germany, where specific psychotherapeutic inpatient treatment settings are a common part of the health care system. In other countries, there are mainly psychiatric facilities whereas in Germany there are also rehabilitation clinics as well as acute hospitals focusing a psychosomatic respectively psychotherapeutic approach (Schulz et al. 2011). In current treatment guidelines (Bandelow et al. 2014; DGBS \& DGPPN 2013; DGPPN et al. 2015), inpatient treatment is recommended when 
301 outpatient treatment is considered as insufficient (e.g. in case of suicidal tendency, profound 302 psychosocial barriers or resistance to outpatient psychotherapy). Unfortunately, there is lack of 303 evidence concerning the choice of the best treatment setting. To give evidence-based 304 recommendations, randomized controlled trials (RCTs) comparing inpatient to outpatient 305 treatment are required. However, the application of RCTs is difficult in this context - as an 306 allocation to a treatment condition of lower intensity would be considered unethical for severely 307 disturbed patients (Liebherz \& Rabung 2014). Thus, the difficulty to meet the decision on inpatient 308 versus outpatient treatment may result from this general lack of evidence or the lack of sufficient 309 information from the health care provider. Moreover, relatives may have experienced a conflict 310 between considering an inpatient treatment as necessary on the one hand and the lack of illness 311 insight of the affected person on the other hand. Relatives may feel overcharged with the affected 312 person's symptoms (e.g. aggression, psychotic symptoms) or medication noncompliance (Gerson $313 \&$ Rose 2012), but they also may be unpleasant with the option of compulsory hospitalization. In 314 the free-text answers, the participants often mentioned related problems like dealing with lack of 315 illness insight or keeping in touch with the affected person in severe illness episodes. To address 316 the relatives' information needs as detailed as possible, further research is needed on the specific 317 difficulties of this decision and on appropriate support possibilities to facilitate this decision.

319 Further research is also required to clarify the reasons for the difficulty of decisions concerning 320 medication. They may result from reasons such as insufficiency of health care providers' education on psychopharmacological treatment, general mistrust in (psychopharmacological) medication

322 (Angermeyer \& Matschinger 2004) or the difficulty in weighing the pros (e.g. response) and cons 323 (e.g. side effects).

325 The results of this survey confirm the importance to address the relatives' needs in mental health 326 care. These findings are, for example, concordant with the current NICE-guideline for schizophrenia and psychosis, which added some special recommendations in the revised version of 2014 (NICE 2014). The guideline proposes health care providers to work in partnerships with the affected persons and their carers (often family members) and furthermore recommends the assessment of carers' needs and the development of plans to address these needs. Moreover, written and verbal information for carers is recommended, including information on diagnosis, 
332 management, outcomes, recovery, support for carers, roles in the health care system and getting

333 help in a crisis. The guideline also addresses the aspect of collaboration and confidentiality and 334 suggests negotiating these issues as soon as possible. Individual needs as well as pros and cons of 335 information sharing about the affected person should be taken into account. Moreover, the 336 guideline recommends including cares in the decision-making process if the affected person 337 agrees.

338

339 The information and decision-support needs of the relatives (e.g. most relevant decision-making 340 topics and high need of general information on the respective disorder) overlap with the affected 341 peoples' needs (Liebherz et al. 2015a; Liebherz et al. 2015b). Previous studies also found that 342 some information needs are overlapping (e.g. the need for general information on the disease and 343 information on coping with symptoms) whereas others are not (e.g. relatives reported higher 344 information needs concerning communication and social relationships and concerning finding a

345 job and employment status) (Gümüş 2008; Pollio et al. 1998; Sung et al. 2004). When designing 346 patient information material, patient decision aids or psychoeducational programs, it is therefore 347 recommendable to include the affected persons', the relatives' as well as the health care provider's 348 ideas and needs.

349 To provide health information, different media (e.g. information leaflets, written online 350 information, videos or podcasts) may be applied. However, exploring a preference for special 351 media was not part of this survey.

\section{Limitations}

354 In this study, it was asked for decisions the affected person had to make and if the relative 355 remembered it as difficult. Thus, these two points of view may have been mixed here and we do not know if the decision was difficult for the affected person, the relative or both. Information and decisional needs and conflicts may therefore result from lack of information through the health care provider or from disagreement or communication problems between the affected person and the relative.

360 Overall, as relatives had to provide information on the affected person's illness and associated treatment decisions, this survey has to deal with recall bias as all information provided are based on the relatives' memory. 
363

364 Since most of the previous research on relatives' needs focused on relatives of patients with 365 affective disorders or schizophrenia, this study aimed at including other psychiatric patients' 366 relatives. Still, the percentage of relatives of patients with other disorders is low (16\%). 367 Furthermore, diagnostic validity is restricted due to self-reported diagnoses. Since the number of 368 participants in some diagnostic subgroups is low, subgroups analyses were not feasible. There is 369 only one study comparing the needs of relatives of patients with affective disorders to relatives of 370 patients with schizophrenia (Mueser et al. 1992). Their needs differed only marginally and only 371 concerning the specific symptoms of the particular disease. Further research on the potential 372 differences between different groups of relatives is therefore recommended.

373 Additional limitations comprise the relatively small sample size as well as the restriction to one 374 country. In other healthcare systems and cultures, other information and decision-making needs 375 may be primarily focused.

376 The recruitment of the participants via an online health information portal suggests that these 377 participants were more likely to have unmet information or decision-making needs, were more 378 (online) health information seeking and perhaps also more likely to prefer an active role in the 379 decision-making process. Thus, the information and decision-support needs of these relatives may 380 not be generalizable.

381

382 To our knowledge, this is the first study on psychiatric patients' relatives' decision-making needs. 383 Thus, and also because of the first application of the purpose-designed questionnaire, the results 384 are exploratory and need to be confirmed in further studies. 


\section{Conclusions}

386 Since psychiatric patients' relatives report extensive information and decision-support needs, it is 387 essential to address their needs in health information material (e.g. information leaflets and patient 388 decision aids). (Online) information appears to be a good opportunity to educate psychiatric 389 patients' relatives on symptoms and treatment possibilities. Relatives are able to access (online) 390 information autonomously - without the affected relative's or the health care professional's 391 support. Still, relatives may feel that they are taken seriously if health care providers also have a 392 focus on their concerns. Their needs may differ from the affected person's needs with regard to 393 some issues. Therefore, their special interests should be considered when designing and evaluating 394 health information material. Additionally, their needs should be addressed in clinical practice. 


\section{Acknowledgements}

396 psychenet is a project network funded by the German Federal Ministry of Education and Research 397 (funding code 01KQ1002B) in the region of Hamburg which consists of more than 100 scientific 398 and medical institutions, counseling centers, the Senate and the Chamber of Commerce of the Free 399 and Hanseatic City of Hamburg, companies, as well as patients' and relatives' associations (2011 $400-2015$ ). The vision of the project is to promote mental health today and in the future, concerning 401 early diagnosis and effective treatment of mental illnesses. For more information and a list of all 402 partners please visit www.psychenet.de.

403 The authors would like to thank Iris Extra for her support in data analysis of the free text fields. 
404 References

405 Ali L, Krevers B, Sjöström N, Skärsäter I. 2014. Effectiveness of web-based versus folder

406

407

408

409

410

411

412

413

414

415

416

417

418

419

420

421

422

423

424

425

426

427

428 support interventions for young informal carers of persons with mental illness: A randomized controlled trial. Patient Education and Counseling 94:362-371.

Angermeyer MC, Diaz Ruiz de Zarate J, Matschinger H. 2000. Informations- und Unterstützungsbedarf von Angehörigen psychiatrischer Patienten [Information and support needs of the family of psychiatric patients]. German. Gesundheitswesen 62:483486.

Angermeyer MC, Matschinger H. 2004. Public attitudes towards psychotropic drugs: have there been any changes in recent years? Pharmacopsychiatry 37:152-156.

Bandelow B, Wiltink J, Alpers G, Benecke C, Deckert J, Eckhardt-Henn A, Ehrig C, Engel E, Falkai P, Geiser F, Gerlach AL, Harfst T, Hau S, Joraschky P, Kellner M, Köllner V, Kopp I, Langs G, Lichte T, Liebeck H, Matzat J, Reitt M, Rüddel HP, Rudolf S, Schick G, Schweiger U, Simon R, Springer A, Staats H, Ströhle A, Ströhm W, Waldherr B, Watzke B, Wedekind D, Zottl C, Zwanzger P, M.E. B. 2014. Deutsche S3-Leitlinie Behandlung von Angststörungen [National Disease Management Guideline Anxiety Disorders]. German. Available at http://www.awmf.org/leitlinien/detail/ll/051-028.html (accessed 02 February 2015).

Beisecker AE, Moore WP. 1994. Oncologists' perceptions of the effects of cancer patients' companions on physician-patient interactions. Journal of psychosocial oncology 12:2339.

Chien WT, Norman I, Chien W-T, Norman I. 2003. Educational needs of families caring for Chinese patients with schizophrenia. Journal of Advanced Nursing 44:490-498.

Degner LF, Sloan JA, Venkatesh P. 1997. The Control Preferences Scale. The Canadian Journal of Nursing Research 29:21-43. 
429 DGBS, DGPPN. 2013. S3-Leitlinie zur Diagnostik und Therapie Bipolarer Störungen.

430

431

432 433

434

435

436

437

438

439

440

441

442

443

444

445

446

447

448

449

450

451

452

453

454

Langversion [S3-Guideline for the diagnosis and treatment of bipolar disorders. Long version]. German. Berlin Heidelberg: Springer.

DGPPN, BÄK, KBV, AWMF, AkdÄ, BPtK, BApK, DAGSHG, DEGAM, DGPM, DGPs, DGRW (Hrsg.) für die Leitliniengruppe Unipolare Depression. 2015. S3-

Leitlinie/Nationale VersorgungsLeitlinie Unipolare Depression - Langfassung, 2. Auflage [S3-Guideline/National Disease Management Guideline Unipolar Depression - Long version, 2nd edition]. German. Available at www.depression.versorgungsleitlinien.de (accessed 18 February 2016).

Dirmaier J, Liebherz S, Sänger S, Härter M, Tlach L. 2016. Psychenet.de: development and process evaluation of an e-mental health portal. Informatics for Health and Social Care 41:267-285.

Elwyn G, Frosch D, Rollnick S. 2009. Dual equipoise shared decision making: definitions for decision and behaviour support interventions. Implementation Science 4:75. DOI: 10.1186/1748-5908-4-75.

Elwyn G, O'Connor A, Stacey D, Volk R, Edwards A, Coulter A, IPDAS Collaboration. 2006. Developing a quality criteria framework for patient decision aids: Online international Delphi consensus process. BMJ (Clinical Research Ed) 333:417-419.

Friedrich F, Unger A, Freidl M, Stelzig-Schöler R, Rittmannsberger H, Simhandl C, Grill W, Doby D, Wancata J. 2012. Prädiktoren für die Belastung von Angehörigen Schizophreniekranker [Risks for Burden among Relatives Caring for Schizophrenia Patients]. German. Psychiatrische Praxis 39:339-344.

Gantt AB, Goldstein G, Pinsky S. 1989. Family Understanding of Psychiatric Ilness. Community Mental Health Journal 25:101-108.

Gaskill D, Cooney H. 1991. Coping with schizophrenia: what does the spouse need to know? Australian Journal of Advanced Nursing 9:10-15. 
455 Gerson LD, Rose LE. 2012. Needs of Persons With Serious Mental Illness Following Discharge

456

457

458

459

460

461

462

463

464

465

466

467

468

469

470

471

472

473

474

475

476

477

478

479

480

From Inpatient Treatment: Patient and Family Views. Archives of Psychiatric Nursing 26:261-271.

Gümüş AB. 2008. Health education needs of patients with schizophrenia and their relatives. Archives of Psychiatric Nursing 22:156-165.

Härter M. 2004. Editorial: Partizipative Entscheidungsfindung (Shared Decision Making) - ein von Patienten, Ärzten und der Gesundheitspolitik geforderter Ansatz setzt sich durch. [Shared decision making - from the point of view of patients, physicians and health politics is set in place]. German. Zeitschrift für Ärztliche Fortbildung und Qualitätssicherung 98:89-92.

Hsieh HF, Shannon SE. 2005. Three approaches to qualitative content analysis. Qualitative Health Research 15:1277-1288.

Laidsaar-Powell RC, Butow PN, Bu S, Charles C, Gafni A, Lam WWT, Jansen J, McCaffery KJ, Shepherd HL, Tattersall MHN, Juraskova I. 2013. Physician-patient-companion communication and decision-making: A systematic review of triadic medical consultations. Patient Education and Counseling 91:3-13. DOI: 10.1016/j.pec.2012.11.007.

Liebherz S, Härter M, Dirmaier J, Tlach L. 2015a. Information and decision-making needs among people with anxiety disorders - results of an online-survey. Patient 8:531-539. DOI: $10.1007 / \mathrm{s} 40271-015-0116-1$.

Liebherz S, Rabung S. 2014. Do patients' symptoms and interpersonal problems improve in psychotherapeutic hospital treatment? - A systematic review and meta-analysis. PLoS ONE 9:e105329. DOI: 10.1371/journal.pone.0105329.

Liebherz S, Tlach L, Härter M, Dirmaier J. 2015b. Information and decision-making needs among people with affective disorders - results of an online survey. Patient Preference and Adherence 9:627-638. DOI: 10.2147/PPA.S78495. 
481

482

483

484 485 486

487 488 489 490

491 492

493

494 495 496

497 498 499

500

501

502

503

504 505 506

Mayring P. 2000. Qualitative content analysis. Forum: Qualitative Social Research 1:Article 20. Available at http://www.qualitative-research.net/index.php/fqs/article/view/1089/2386. (accessed 27 April 2017).

Mueser KT, Bellack AS, Wade JH, Sayers SL, Rosenthal CK. 1992. An assessment of the educational needs of chronic psychiatric patients and their relatives. The British Journal of Psychiatry 160:674-680.

NICE. 2014. Psychosis and Schizophrenia in Adults. The NICE guideline on the treatment and management (updated edition). National Clinical Guideline Number 178. National Collaborating Centre for Mental Health. Commissioned by the National Institute for Health and Care Excellence.

Pollio DE, North CS, Foster DA. 1998. Content and Curriculum in Psychoeducation Groups for Families of Persons With Severe Mental Illness. Psychiatric Services 49:816-822.

QuestBack. 2012. Enterprise Feedback Suite. EFS Survey. 9.0/1.0 ed: QuestBack AG.

Schulz H, Barghaan D, Koch U, Harfst T. 2011. Die Versorgung von Patienten mit psychischen Störungen [Health care for patients with mental disorders]. German. In: Wittchen H-U, Hoyer J, eds. Klinische Psychologie \& Psychotherapie. 2. ed. Berlin: Springer, 361-380.

Skundberg-Kletthagen H, Wangensteen S, Hall-Lord M-L, Hedelin B. 2014. Relatives of patients with depression: experiences of everyday life. Scandinavian Journal of Caring Sciences 28:564-571.

SPSS. 2009. PASW 18 Command syntax reference. Chicago, Illinois: SPSS Inc.

Sung S-C, Hixson A, Crofts Yoker B. 2004. Predischarge psychoeducational needs in Taiwan: Comparisons of psychiatric patients, relatives and professionals. Issues in Mental Health Nursing 25:579-588.

Tlach L, Wüsten C, Daubmann A, Liebherz S, Härter M, Dirmaier J. 2015. Information and decision-making needs among people with mental disorders: A systematic review of the literature. Health Expectations 18:1856-1872. DOI: 10.1111/hex.12251. 
507 Wancata J, Krautgartner M, Berner J, Scumaci S, Freidl M, Alexandrowicz R, Rittmannsberger

508 H. 2006. The "Carers' needs assessment for Schizophrenia". Social Psychiatry and $509 \quad$ Psychiatric Epidemiology 41:221-229.

510 Wei SJ, Cooke M, Moyle W, Creedy D, Wei S-J, Cooke M, Moyle W, Creedy D. 2010. Health

511

512

513

514

515

516

517

518

519

520

521

522

523

524 525

526 education needs of family caregivers supporting an adolescent relative with schizophrenia or a mood disorder in taiwan. Archives of Psychiatric Nursing 24:418-428.

Weimand BM, Hedelin B, Sällström C, Hall-Lord M-L. 2010. Burden and Health in Relatives of Persons with Severe Mental Illness: A Norwegian Cross- Sectional Study. Issues in Mental Health Nursing 31:804-815.

Weymann N, Härter M, Petrak F, Dirmaier J. 2013. Health information, behavior change, and decision support for patients with type 2 diabetes: development of a tailored, preferencesensitive health communication application. Patient Preference and Adherence 7:10911099. DOI: 10.2147/Ppa.S46924.

Wittmund B, Bischkopf J, Angermeyer MC. 2001. Wie nehmen Lebenspartner depressiver Patienten die Krankheit wahr und welche Informationen brauchen sie? [Educational needs among spouses of depressive patients and their illness models of depression]. German. Gesundheitswesen 63:536-541.

Wolff JL, Roter DL. 2008. Hidden in plain sight: medical visit companions as a resource for vulnerable older adults. Archives of Internal Medicine 168:1409-1415. 
Table $\mathbf{1}$ (on next page)

Sample description 


\begin{tabular}{|c|c|c|}
\hline Characteristics & $\mathbf{N}$ & $\%$ \\
\hline \multicolumn{3}{|l|}{ Sex } \\
\hline female & 143 & 77 \\
\hline male & 42 & 23 \\
\hline Age in years $(M \pm S D$, range $)$ & $48.6 \pm 12.9,19-82$ & \\
\hline \multicolumn{3}{|l|}{ Education } \\
\hline $8-10$ years & 53 & 29 \\
\hline more than 10 years & 129 & 70 \\
\hline other (still at school, without graduation, other) & 3 & 2 \\
\hline \multicolumn{3}{|l|}{ Relationship } \\
\hline living in a permanent relationship & 146 & 79 \\
\hline \multicolumn{3}{|l|}{ Country of birth } \\
\hline Germany & 170 & 92 \\
\hline \multicolumn{3}{|l|}{ Affected relative (multiple answers) } \\
\hline my partner & 62 & 34 \\
\hline my mother/father & 40 & 22 \\
\hline my daughter/son & 64 & 35 \\
\hline other relatives & 33 & 18 \\
\hline A friend/acquaintance & 13 & 7 \\
\hline Other (i.e. ex-partner) & 5 & 3 \\
\hline \multicolumn{3}{|l|}{ Main diagnosis } \\
\hline Alcohol misuse or additction & 3 & 2 \\
\hline Schizophrenia/psychosis & 38 & 21 \\
\hline Bipolar disorder/mania & 84 & 45 \\
\hline Depression & 27 & 15 \\
\hline Anxiety disorder & 5 & 3 \\
\hline Somatoform disorder & 6 & 3 \\
\hline Eating disorder & 2 & 1 \\
\hline other & 14 & 8 \\
\hline I don't know & 6 & 3 \\
\hline
\end{tabular}




\section{Table 2 (on next page)}

Online health information needs $(\mathrm{N}=185)$

a The relative's mental illness previously mentioned was named here. 


\begin{tabular}{lrr}
\hline & $\mathrm{N}$ & $\%$ \\
\hline Information for relatives & 130 & 70 \\
General information on . $^{\text {a }}$ (symptoms, causes, course of the disease) & 125 & 68 \\
Tips on dealing with the disease (e.g. coping with everyday life, self-help) & 115 & 62 \\
Information about treatment options (e.g. psychotherapy, drugs) & 111 & 60 \\
Information about chances, risks, and side effects of the treatment options & 99 & 54 \\
Information about self-help groups / exchange with affected / reported experiences of those affected & 80 & 43 \\
Information on psychotherapists, physicians, clinics (e.g. Where can I get treatment?) & 46 & 25 \\
\hline
\end{tabular}




\section{Table 3 (on next page)}

Treatment decisions concerning the affected person $(\mathrm{N}=185)$, figures in $\%$ 


\begin{tabular}{|c|c|c|c|}
\hline taking psychotropic drugs or not & 58 & 29 & 12 \\
\hline taking another medication or a different dose & 49 & 23 & 29 \\
\hline starting a psychotherapy or not & 48 & 34 & 18 \\
\hline which psychotropic drugs to take & 48 & 30 & 22 \\
\hline $\begin{array}{l}\text { taking psychotropic drugs in addition to the ongoing } \\
\text { psychotherapy or not }\end{array}$ & 37 & 22 & 42 \\
\hline quit the current psychotherapy or not & 32 & 16 & 53 \\
\hline doing physical training or not & 24 & 45 & 30 \\
\hline attending a psychotherapy OR taking psychotropic drugs & 23 & 16 & 62 \\
\hline working through a self-help book or not & 20 & 25 & 55 \\
\hline
\end{tabular}


Figure 1

Internet use $(\mathrm{N}=185)$

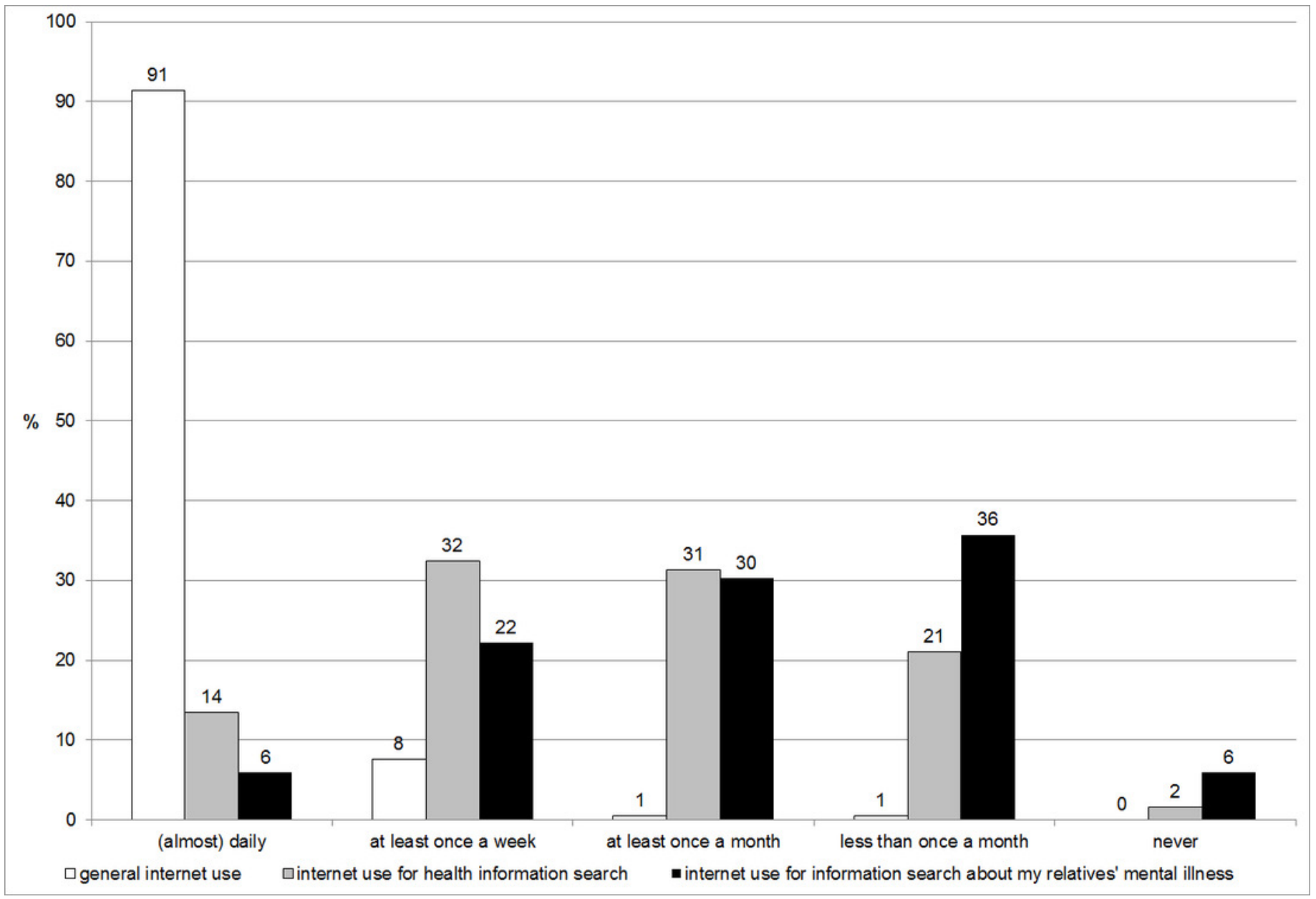




\section{Figure 2}

\section{Reasons for searching the internet $(\mathrm{N}=185)$}

a The relative's mental illness previously mentioned was named here.

\begin{tabular}{|l}
\hline I wanted to inform myself generally about ... \\
The information the physician / psychotherapist provided \\
were not sufficient. \\
I did not agree with the information the physician / \\
psychotherapist provided. \\
I am looking for a physician / psychotherapist. \\
$\begin{array}{r}\text { The information the physician / psychotherapist provided } \\
\text { were difficult to understand. }\end{array}$ \\
$\begin{array}{r}\text { It was recommended by the physician / psychotherapist to } \\
\text { read up on .... }\end{array}$
\end{tabular}


Figure 3

Preferred and experienced decision-making role (in \%, $\mathrm{N}=185$ )

my relative and the physician or psychotherapist

mainly the physician or psychotherapist

only the physician or psychotherapist

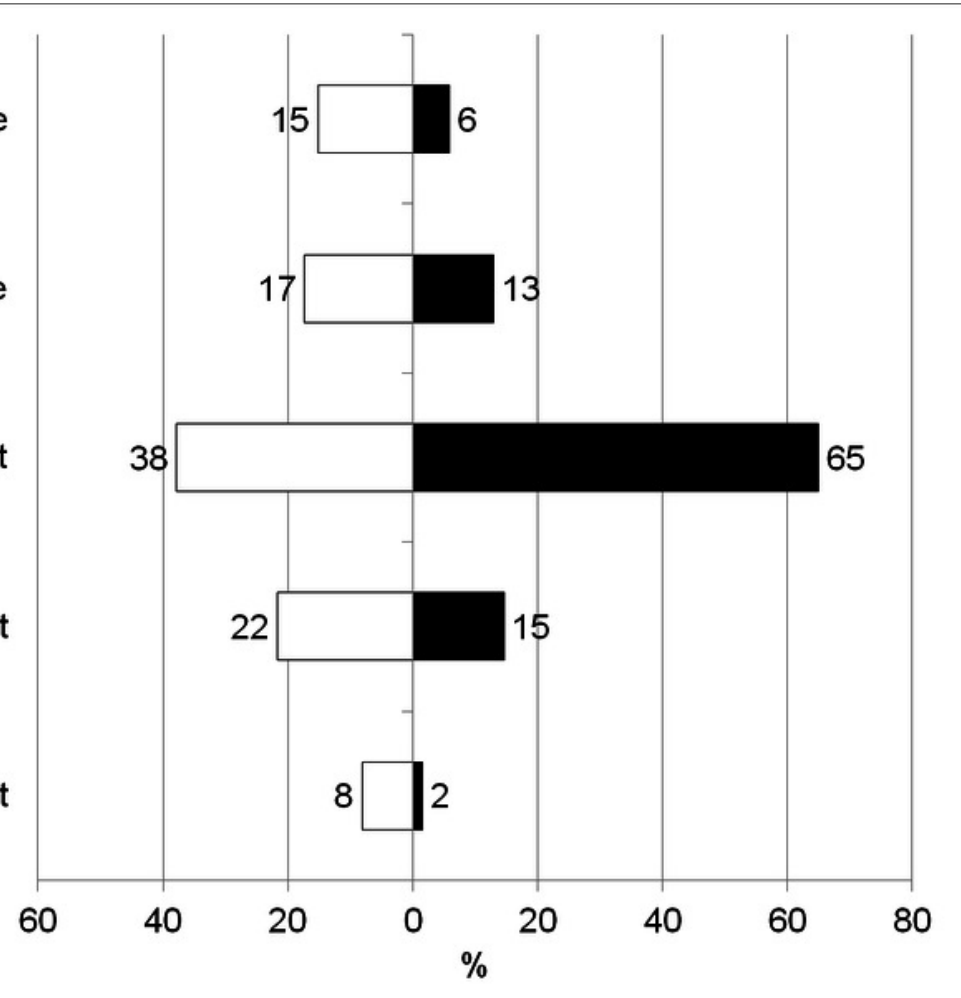

-Who should decide? $\quad$ Who did decide? 